\title{
Quiet Apprehension: Reading and Classroom Anxieties
}

\author{
Sae Matsuda \\ Kyoto Sangyo University \\ Peter Gobel \\ Kyoto Sangyo University
}

Although many studies of foreign language anxiety focus on the difficulties caused by anxiety with respect to classroom activities such as speaking and listening, this study investigates the possible relationship between general foreign language classroom anxiety (FLCA) and foreign language reading anxiety (FLRA) in the Japanese classroom. Using previously published measurement scales (the FLCAS and the FLRAS), this study seeks first to determine the reliability and validity of the individual scales across three different groups in nine intact first-semester English classes (252 students) at a Japanese university. Based on this data, the possible relationships between the two theoretical constructs of foreign language classroom anxiety and foreign language reading anxiety, and the variable of class group are explored. The results of the study suggest that although subcomponents of the two scales are related, overall FLCAS and FLRAS are measuring two clearly independent constructs. In addition, anxiety types measured also differed significantly depending on group membership.

これまで外国語学習における不安 (anxiety) はスピーキングやリスニング などのクラス活動の分野に重点を置いて研究されてきたか、この研究では、外 国語のクラスにおける一般的な不安(FLCA)と外国語のリーティングに対する不 安(FLRA)に相関関係があるかを探った。既存の測定尺度(FLCASとFLRAS)を 用い、日本の大学生 (1 年生から 3 年生までの 252 人) を対象に、まず各尺 度の信用性と有効性を調べた。そのテータを基に、外国語のクラスに対する不 安(FLCA)と外国語のリーティングに対する不安(FLRA)という二つの理論上の 構成体には相関関係があるか、そして不安の型には学年による違いが見られる かを分析した。その結果、FLCASとFLRASは細部では関連が見られるものの、 全体としては明確に独立した構成体であること、不安の型には学年によって顕 著な違いが見られることがわかった。

$\mathbf{R}$ esearchers in different fields have long recognized the existence of anxiety and its potential for interference with performance (e.g., Alpert \& Haber, 1960; Eysenck, 1979; Spielberger, 1983). 
Their general perspectives on anxiety set the groundwork for the development of Horwitz, Horwitz, and Cope's (1986) definition of foreign language anxiety as a complex set of self-perceptions, beliefs, feelings, and behaviors related specifically to classroom language learning and the language learning process. They claim three types of anxiety as their theoretical basis: communication apprehension, test anxiety, and fear of negative evaluation. In an effort to psychometrically assess these three types of anxiety underlying foreign language anxiety, Horwitz et al. developed the Foreign Language Classroom Anxiety Scale (FLCAS) as a standard instrument (Horwitz et al., 1986). Horwitz also studied student beliefs about language learning (Horwitz, 1988) and stressed that affective consequences of these beliefs must be considered. The results of this study, for example, suggest that a significant number of students put stress on grammatical accuracy, which Horwitz identifies as a contributing factor to anxiety in foreign language learning.

Tobias (1986) created a separate taxonomy of anxiety and suggested a framework containing three distinct subconstructs of anxiety in language learning: input, processing, and output. Tobias claimed that anxious learners have greater difficulty registering information (input), cognitive operations (processing), and production (output) than do less anxious learners. Macintyre and Gardner $(1989,1991 \mathrm{~b})$ also investigated various types of anxiety scales and tried specifically to assess foreign language anxiety. They concluded that foreign language anxiety is a situation-specific form of anxiety unrelated to other forms of anxiety. They also examined the relationship between foreign language anxiety and foreign language proficiency. Although their findings yielded two distinct constructs in foreign language anxiety in support of Horwitz et al. (1986), they concluded that test anxiety is a more general problem that is not necessarily specific to the language classroom. They also supported Tobias' (1986) theory by obtaining a negative correlation between anxiety and the learning (input) and production (output) of French vocabulary.

\section{Anxiety and Language Learning}

A review of the literature shows the negative relationship between anxiety and foreign language learning. Significant negative correlations between test anxiety, final course grades, and high competitiveness in class, which leads to anxiety and thus impairs learners' progress and/ or performance, are often reported (e.g., Aida, 1994; Bailey, 1983; Chastain, 1975; Phillips, 1992). One possible explanation for these re- 
sults may be the negative effect anxiety has on memory and recall (MacIntyre \& Gardner, 1991b; MacIntyre \& Gardner, 1994b). Another possible explanation may be the effect embarrassment and anxiety has on classroom performance (Saito \& Samimy, 1996; Ely, 1986; Samimy \& Tabuse, 1992). In addition to negative changes in performance, research suggests that foreign language anxiety affects learners' classroom behaviors in general (cf. Horwitz et al., 1986; Young, 1991).

In contrast, a number of studies have suggested that the effects of foreign language anxiety are not always negative. Bailey (1983) found that facilitative anxiety was one of the keys to success, pointing out that although too much anxiety had a negative effect, moderate amounts of anxiety produced positive results. In other words, a certain amount of anxiety, combined with sufficient motivation and enough time, may be beneficial to performance in the target language (e.g., Gardner \& MacIntyre, 1992; MacIntyre \& Gardner, 1994b; Tobias, 1986).

Research has also suggested that levels of FL anxiety vary according to instructional levels, although there is little agreement on where the most or least anxiety lies. Gardner, Smythe, Clement, and Gliksman (1976) found that French-class anxiety correlated more strongly with proficiency as the students entered higher grade levels. On the other hand, Gardner, Smythe, and Brunet (1977) found the highest anxiety existed in the beginners' classes while the least anxiety was observed in the advanced and intermediate classes. Saito and Samimy (1996) obtained a somewhat different result, exploring the impact of anxiety on learners of Japanese at beginning, intermediate, and advanced levels. Their results suggest that advanced learners display the highest anxiety levels, while intermediate students scored the lowest and beginning students fell between the two. The conflicting findings of these three studies suggest that influences on anxiety are quite dynamic, with factors such as experience with the target language playing a key role.

It has also been hypothesized that the initial level of anxiety could change depending upon learners' experiences and proficiency. MacIntyre and Gardner (1991a) claim that positive experiences with the target language and observable achievement in the classroom help to reduce anxiety. A number of studies have dealt with the effect of immersion or intensive courses and their effect on anxiety (Chapelle \& Roberts, 1986; Desrochers \& Gardner, 1981; Gardner et al., 1977; Gardner, Smythe, \& Clement, 1979). The results of these studies indicate that anxiety levels are notably lower following positive intensive language learning experiences, regardless of L2 proficiency, target lan- 
guage, or age,

Research points to oral classroom activities as some of the most problematic and anxiety-provoking activities for foreign language learners (Horwitz et al., 1986; MacIntyre \& Gardner, 1994a; Price, 1991; Mejias, Applebaum, Applebaum, \& Trotter, 1991; Steinberg \& Horwitz, 1986). Students experience significantly higher anxiety when responding orally than when doing other learning tasks, and this anxiety is observable in oral production. Students in the anxiety-producing situation of oral language production tend to respond less interpretively and attempt more concrete messages than those in relaxed conditions.

Several researchers have attempted to measure apprehension specific to FL reading and writing. Cheng, Horwitz, and Schallert (1999) investigated the relationship between L2 classroom anxiety and L2 writing anxiety of university English majors in Taiwan using translated versions of the Daly-Miller (1975a, 1975b) Writing Apprehension Test (SLWAT) and the Foreign Language Classroom Anxiety Scale (FLCAS). They found that while L2 classroom anxiety involves a more general type of anxiety that focuses on speaking apprehension, L2 writing anxiety is the more specific type dealing with the language-particular skill of writing. In their detailed factor analysis, they reported a five-component solution: two components (Low Self-confidence in Speaking English and General English Classroom Performance Anxiety) from the FLCAS and three components (Low Self-confidence in Writing English, Aversion to Writing in English, and English Writing Evaluation Apprehension) from the SLWAT.

Reading anxiety has also been studied in FL settings. Saito, Garza, and Horwitz (1999) used the FLCAS and the FLRAS (Foreign Language Reading Anxiety Scale, specifically developed to assess reading apprehension) to investigate links between general FL anxiety and FL reading anxiety. They wanted to see whether learners ${ }^{\prime}$ FL anxiety influences their FL reading anxiety. They found that FL reading anxiety is related to but distinguishable from general FL anxiety and that reading anxiety increased as learners' perceptions of the difficulty of the reading increased. Various levels of reading anxiety were found depending on the different target languages studied. In contrast, Macintyre, Noels, and Clement (1997), in their study of biases in self-ratings of second language proficiency in different skills, found similar levels of bias in speaking, writing, and comprehension, but not in reading. They claim that this is because reading is, for the most part, a "private task" in which repetitions and clarifications are silently performed, thus limiting risks of embarrassment. 


\section{Statement of Purpose}

Thus far, a large body of research has dealt with communication-related anxiety in the foreign language classroom, but it seems that only a limited number of studies have been conducted to specifically measure reading anxiety. Is reading such a private task that students are unlikely to feel anxious about it as MacIntyre et al. (1997) suggest? We began to question their view when several students in our third-year reading class told us that they often feel nervous and have trouble concentrating when they have to read in English. They claimed that they often end up reading the same sentences repeatedly without comprehension. As Saito et al. (1999) put it, "at first glance, reading would seem to be the component of FL performance least susceptible to anxiety effects" (p. 202). However, it became apparent that some students may be experiencing quiet apprehension in their L2 reading classes.

The purpose of this study is to explore foreign language classroom anxiety (FLCA) and foreign language reading anxiety (FLRA) in the Japanese EFL classroom. Previous studies and measurement scales were the logical starting point for this undertaking. Although questionnaires such as the FLCAS and FLRAS had been carefully developed and their reliability reported, the original forms of these questionnaires were developed with a specific population in mind. Consequently, establishing the reliability and validity of the forms used in this study was a primary concern. We then attempted to determine what, if any, relationship exists between these two concepts of anxiety and whether this relationship differs depending on group membership, operationalized as class level.

The following research questions were explored in this study:

1. Is there a relationship between general English classroom anxiety and English reading anxiety?

2. Are there differences in types of anxiety based on the school year?

\section{Method}

\section{Participants}

A total of 252 students majoring in English at a large university in Kyoto participated in the research. Three classes each from the first-year, second-year, and third-year courses were chosen at random to represent their year. The subjects consisted of 89 first-year, 85 second-year, and 78 third-year students. Their proficiency in English ranged from high beginner to high intermediate, with all classes containing mixed 
proficiencies. The majority of the high beginners were in the first-year classes. Student ages ranged from 18 to 21. As in Cheng et al. (1999), the classes of English majors were dominated by female students, with a male-female ratio of 75:177 (see Table 1).

Naturally, school curricula vary according to the school year. Firstyear students, following a recently introduced curriculum, met three times a week for what is called "four skills" classes and also three times for "content-based" classes in which they study in five different content areas in English (Environmental Issues, British Culture, Australian Culture, Music, and Japanese Culture) for five weeks each. Secondand third-year students are in separate curricula. Second-year students received six distinct classes per week, including intensive reading, extensive reading, grammar, writing, speaking, and listening. Third-year students met five times a week for intensive reading, extensive reading, business writing, a "content-based" class, and a seminar.

Table 1: Participant Data

\begin{tabular}{lcccc}
\hline Year & Participants & Male & Female & Hours of English/week \\
\hline First & 89 & 23 & 66 & 9.0 \\
Second & 85 & 29 & 56 & 9.0 \\
Third & 78 & 23 & 55 & 7.5 \\
\hline
\end{tabular}

\section{Materials}

Two instruments were used in this study: the FLCAS (Horwitz et al., 1986) and the FLRAS (Saito et al, , 1999). The instruments were designed to elicit students' self-reports regarding anxiety, either over various aspects of reading in a foreign language (FLRAS) or over general classroom anxiety in a foreign language class (FLCAS). All items on both instruments were answered on a 5-point Likert scale, ranging from "strongly agree" to "strongly disagree." The FLCAS contained 33 items, and the FLRAS contained 20 items. In order to ensure that questionnaire items were clearly understood, the Japanese researcher in this study translated both questionnaires into Japanese, and the translation was placed underneath each original English equivalent. The translation was then back translated and checked by a bilingual Japanese colleague and a bilingual native speaker of English to make sure that the original meaning had not been altered. The only necessary changes to the wording of the original instruments were cases where the words 
"foreign language" and "language," found in the original FLCAS and FLRAS, were replaced with "English," and "the teacher" was changed to "the English teacher."

\section{Procedures}

The FLCAS was administered in the 8 th week and FLRAS in the 10th week of the Spring semester of 2000 . Students were reminded that they were not to answer the items based on the specific class where the questionnaires were administered, but rather based on general English classes or English reading classes. Two Japanese teachers and a native speaker teacher administered the questionnaires to the firstyear students in their "four skills" classes. The questionnaires for the second-year students were administered by Japanese teachers in one reading and two listening classes. The third-year students received the questionnaires from two Japanese and one native speaker teacher in their reading classes.

Students who filled out the FLCAS but were absent in the 10th week were asked to fill out the FLRAS in the 11 th week. Likewise, students who missed the FLCAS in the 8th week were told to fill it out in the 11 th week. Students who did not complete a questionnaire or could not be located to fill out both questionnaires were eliminated from the study, thus slightly reducing the number of participants. Data collection was for the most part successful for each target group, with $95.7 \%$ of the first-year, $93.4 \%$ of the second-year, and $92.2 \%$ of the third year students' data being collected.

\section{Analysis}

The reliability of the two instruments was determined using Cronbach's alpha. Construct validity, the ability of the questionnaire to measure what it purports to measure, and the interrelationship among the items included in the questionnaire was determined by a principal component analysis. The principal component analysis was carried out on a Macintosh computer using the STATISTICA (1994) software package. A varimax rotation was used and eigenvalues greater than 1.0 and meeting the scree plot criteria were retained. Significant differences between variables and their interactions were explored using MANOVA and Pearson $r$, following principal component analysis. An alpha level of .05 was set for all statistical procedures. 


\section{Results}

Reliability of the FLCAS and the FLRAS

Although reliability of both instruments has been previously reported (Cheng et al, 1999; Horwitz et al., 1986; Saito et al., 1999), the reliability in these previous cases is not relevant to our translated versions nor to the population of this study. Therefore, internal consistency was computed for each of the Japanese versions of the FLCAS and the FLRAS. Cronbach's alpha for the FLCAS was $0.78(N=252, M=100.75$, and $S D$ $=11.43)$ and for the FLRAS it was $0.71(N=252, M=61.26$, and $S D=$ 7.33). These values were lower than expected, and much lower than the values reported in Cheng et al. (1999) and Saito et al. (1999). Kurtosis and skewness help determine whether a distribution is normal, and here kurtosis was .037 for FLCAS and .339 for the FLRAS and skewness was .140 and .089 for the two tests, respectively, indicating normal distribution. ${ }^{1}$ See Table 2 for descriptive statistics by test and year.

Table 2: Descriptive Statistics for FLCAS and FLRAS

\begin{tabular}{|c|c|c|c|c|}
\hline & Total & Year 1 & Year 2 & Year 3 \\
\hline \multicolumn{5}{|l|}{ FLCAS } \\
\hline Total & 25394.000 & 8894.000 & 8477.000 & 8023.000 \\
\hline Mdn & 101.000 & 99.933 & 102.000 & 102.000 \\
\hline mode & 98.000 & 11.986 & 101.000 & 96.000 \\
\hline M & 100.770 & 100.000 & 99.729 & 102.859 \\
\hline SD & 11.428 & 98.000 & 10.910 & 11.192 \\
\hline $\min$ & 72.000 & 73.000 & 72.000 & 73.000 \\
\hline $\max$ & 133.000 & 128.000 & 125.000 & 133.000 \\
\hline kurtosis & 0.037 & $-0,109$ & 0.122 & 0.087 \\
\hline skewness & 0.140 & 0.221 & 0.057 & 0.082 \\
\hline $\mathrm{N}$ & 252 & 89 & 85 & 78 \\
\hline \multicolumn{5}{|l|}{ FLRAS } \\
\hline Total & 15437.000 & 5278.000 & 5327.000 & 4832.000 \\
\hline Mdn & 62.000 & 59.000 & 63.000 & 61.000 \\
\hline mode & 61.000 & 54,000 & 62.000 & 64.000 \\
\hline M & 61.258 & 59.303 & 62.671 & 61.949 \\
\hline SD & 7.326 & 7.096 & 7.493 & 7,004 \\
\hline $\min$ & 41.000 & 43.000 & 41.000 & 43.000 \\
\hline $\max$ & 89.000 & 79.000 & 78.000 & 89.000 \\
\hline kurtosis & 0.339 & -0.260 & 0.285 & 2.067 \\
\hline skewness & 0.089 & 0.228 & -0.530 & 0.722 \\
\hline $\mathrm{N}$ & 252 & 89 & 85 & 78 \\
\hline
\end{tabular}




\section{Structure of the Questionnaires}

To explore the component structure of each of the questionnaires (i.e., to see which items grouped together based on subject response), an exploratory principal component analysis with varimax rotation was performed. Following this, correlation coefficients (a numerical measure of the degree of agreement between two sets of scores) were computed to determine the associations among factors in each of the questionnaires. Principal component analysis is sensitive to the size of the correlation, requiring a rather large sample size. Although there is no total agreement among statisticians regarding what constitutes a large enough sample size, Tabachnick and Fidell (1996) suggest 300 cases as a minimum. Consequently, the sample size for this study (252) does not meet this criterion. On the other hand, the assumption of a ratio of 20:1 for subjects to factors and 2:1 for subjects to variables (STATISTICA, 1994) was met by the present data.

\section{Principal Component Analysis of the FLCAS}

A principal component analysis with varimax rotation produced seven factors with eigenvalues greater than one. Retaining all seven factors would create a model too complex for our purposes, so a smaller number of factors was extracted. The number of factors to extract in the study was based on two methods: the first being that previous research determined a two-factor solution and the second being a standard statistical analysis using a scree plot. If the eigenvalues are plotted on a graph, the place where the smooth decrease of eigenvalues appears to level off is the cutoff point. All eigenvalues to the left of the cutoff point will be retained as factors in the matrix. The scree plot was chosen over the more familiar Kaiser criterion based on evidence that the Kaiser criterion sometimes retains too many factors (Kline, 1994; STATISTICA, 1994) and based on the interpretability of a two-factor versus a seven-factor solution. Looking at a scree plot of the eigenvalues for this study showed that the plot turned right following Factor 2 (see Figure 1). The last five factors were thus discarded. If the current model based on two factors is correct, then the two factors will explain a substantial amount of variance in all items. The percent of variance explained for each factor and the total percent explained can be found in Table 3. 


\section{Figure 1: Scree Plot of Eigenvalues for FLCAS}

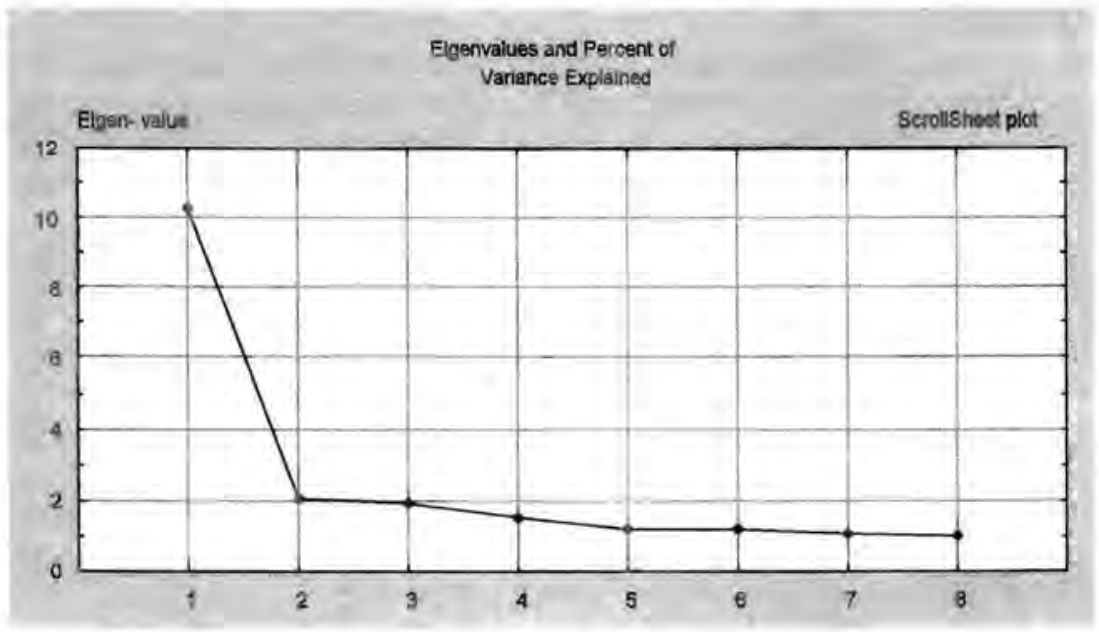

Table 3: Results of Factor Analysis for FLCAS

Item\#

Questionnaire items

F1

F2 $\quad h^{2}$

2. I don't worry about making mistakes in English class.

3. I tremble when I know that I'm going to be called on in English class. -.657

4. It frightens me when I don't understand what the teacher is saying in English.

8. I am usually at ease during tests in my English class.

9. I start to panic when I have to speak without preparation in English class.

12. In English class, I can get so nervous I forget things I know.

13. It embarrasses me to volunteer answers in my English class.

14. I would not be nervous speaking English with native speakers. .583

16. Even if I am well prepared for English class, I feel anxious about it.

$-.652$

19. I am afraid that my English teacher is ready to correct every mistake I make.

20.1 can feel my heart pounding when I am going to be called on in my English class.

22. I don't feel pressure to prepare very well for English class.

24. I feel very self-conscious about speaking English in front of other students.

26. I feel more tense and nervous in my English class than in my other classes.

27. I get nervous and confused when I am speaking in my English class.

29. I get nervous when I don't understand every word the English teacher says.

30. I feel overwhelmed by the number of rules you have to learn to speak English. 
Table 3 (Continued)

\begin{tabular}{|c|c|c|c|}
\hline Questionnaire items. & F1 & $\mathrm{F} 2$ & $h^{2}$ \\
\hline $\begin{array}{l}\text { 25. English class moves so quickly I worry about getting left behind. } \\
\text { 33. I get nervous when the English teacher asks questions }\end{array}$ &. .447 & .424 & 4.380 \\
\hline which $I$ haven't prepared in advance. & -.623 & & .454 \\
\hline $\begin{array}{l}\text { 1. I am afraid that the other students will laugh at me } \\
\text { when I speak English. }\end{array}$ & -.626 & & .408 \\
\hline 21. The more I study for an English test, the more confuse & & .322 & 2.199 \\
\hline 1. I never feel quite sure of myself when I am speaking in English. & & .604 & 4.562 \\
\hline $\begin{array}{l}\text { 5. It wouldn't bother me at all to take more English classes. } \\
6 \text {. During English class, I find myself thinking about things that }\end{array}$ & & .618 & 8.384 \\
\hline She & & .977 & 7.256 \\
\hline $\begin{array}{l}\text { 7. I keep thinking that the other students are better at English } \\
\text { than I am. }\end{array}$ & & .573 & 3.420 \\
\hline bout the consequences of failing my English class. & & 511 & .358 \\
\hline 7. 10 & & 697 & 7.489 \\
\hline 18. I feel confident when I speak in my English class. & & -.577 & 7.444 \\
\hline $\begin{array}{l}\text { 23. I always feel that the other students speak English better } \\
\text { than I do. }\end{array}$ & & .560 & 0.388 \\
\hline $\begin{array}{l}\text { 28. When I'm on my way to English class, I feel very sure } \\
\text { and relaxed. }\end{array}$ & & 570 & .488 \\
\hline . I would probably fee & & & \\
\hline of Engl & & .435 & 339 \\
\hline Eigen & 10.26 & 2.0 & \\
\hline Percentage o & 31.09 & 6.18 & \\
\hline Cumulative percentage of total variance & 31.09 & 37.2 & 28 \\
\hline
\end{tabular}

The communalities shown to the right in Table 3 are the proportions of variance of each item due to the common factors. If the present model is correct, then the values will be generally homogeneous. This two-component solution is similar to Cheng et al. (1999); however, unlike their study, which excluded items with factor loadings less than .50 and/or double loadings within .20 of the primary loading, this study included all items in the analysis with loadings greater than .30 , regardless of double loadings. These factor loadings represent the correlation of a variable with a factor, and loadings of .30 or more are considered to be significant (Kline, 1994). Consequently, only items 11 and 15 were deleted based on low factor loadings and communalities.

The first factor, which accounted for $31.1 \%$ of the variance included items related to anxiety, fear, and pressure related to performance in the English classroom. In particular, the two items with the highest loadings on Factor 1, items 26 ("I feel more tense and nervous in my English class than in my other classes") and 27 ("I get nervous and confused when I am speaking in my English class") reflect students' anxi- 
ety about classroom performance. Therefore, this component was labeled General English Classroom Performance Anxiety (FLCA1).

The second factor, which accounted for $6.2 \%$ of the total variance. included items not specifically related to performance in the classroom. Many of the items that loaded on Factor 2 were concerned with selfconfidence in English ability, such as item 1 ("I never feel quite sure of myself when I am speaking in English"). In addition to these, the items that loaded the highest on Factor 2 were items pertaining to attending English classes such as items 5 and 17. Since these could be related to general self-confidence, factor 2 was labeled Low Self-Confidence in Speaking English (FLCA2).

\section{Principal Component Analysis of the FLRAS}

Using the same procedure described above, a principal component analysis of FLRAS suggested a three-component solution, which accounted for $40.89 \%$ of the total variance (Table 4). Items 15 and 16 were deleted based on their low factor loadings and low communalities, and item 2, which double loaded on factor 1 and factor 2 , was also deleted for the purpose of clarity.

Items in factor 1, which accounted for approximately $21 \%$ of the total variance, were mainly concerned with grammar and vocabulary. The items that loaded the highest on this factor were item 6 ("I get upset whenever I encounter unknown grammar when reading English") and item 8 ("It bothers me to encounter words I can't pronounce while reading English"). Therefore, this factor was labeled Familiarity with English Vocabulary and Grammar (FLRA1).

Factor 2 , accounting for $11.79 \%$ of the total variance, was concerned mainly with confidence in reading English and reading enjoyment. Item 12 ("I enjoy reading in English") and item 13 ("I feel confident when I am reading in English") were representative of factor 2 and so this factor was labeled Reading Confidence/Enjoyment (FLRA2).

Factor 3 accounted for $8.1 \%$ of the total variance and included a variety of items, making it difficult to label this factor. The highest loading for factor 3 was item 19 ("English culture and ideas seem very foreign to me") but other items with almost equally high loadings were item 9 ("I usually end up translating word by word when I am reading English in front of me") and item 11 ("I am worried about all the new symbols you have to learn in order to read English"). Since these items dealt either with English culture or ideas, as well as the English writing system, this factor was labeled Language Distance (FLRA3) (See Table 4). 
Table 4: Results of Factor Analysis for FLRAS

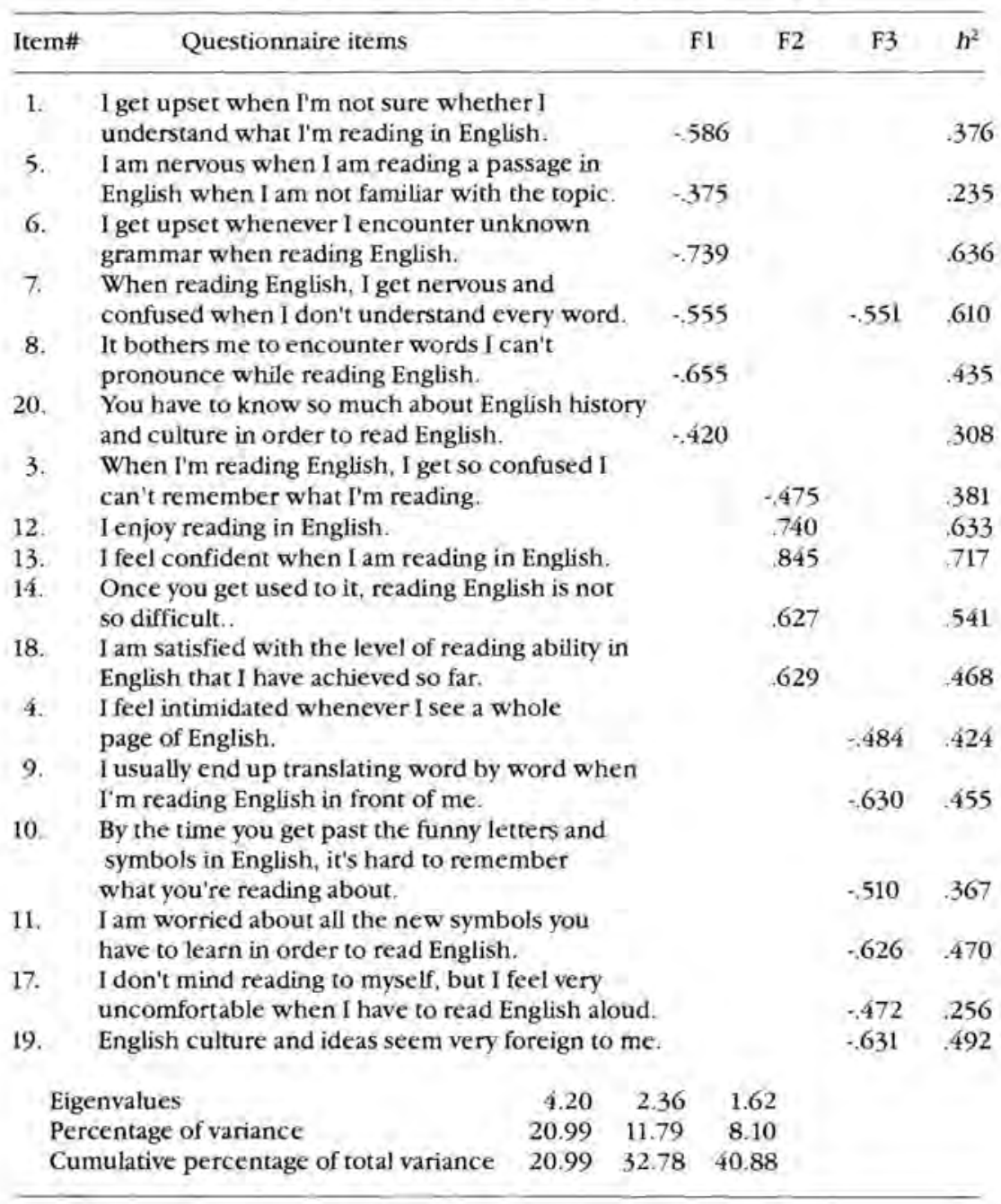

\section{Correlations among the Questionnaires and Their Subcomponents}

Based on the results of the above two principal components analyses, Pearson correlations were computed for the FLCAS and FLRAS and their subcomponents using factor scores derived from the principal component analyses. Table 5 presents the correlation matrix. FLCA1 (General English Classroom Performance Anxiety) correlates significantly with FLRA1 (Familiarity with English Vocabulary and Grammar) and 
FLRA3 (Language Distance). This suggests the obvious connection between familiarity with the FL and performance anxiety. FLCA2 (Low Self-confidence in Speaking English) correlated significantly with two of the factors in FLRAS: Reading Confidence/Enjoyment (FLRA2) and Language Distance (FLRA3), suggesting that self-confidence in speaking and reading are related and that familiarity with the mechanics of English is also related to self-confidence.

Table 5: Pearson Correlation Matrix

\begin{tabular}{lccccc} 
& FLRA1 & FLRA2 & FLRA3 & FLCA1 & FLCA2 \\
\hline FLRA1 & 1.000 & & & & \\
FLRA2 & .002 & 1.000 & & & \\
FLRA3 & .000 & .000 & 1.000 & & \\
FLCA1 & $.413^{*}$ & -.066 & $.259^{*}$ & 1.000 & \\
FLCA2 & -.023 & $.390^{*}$ & $-.298^{*}$ & .000 & 1.000 \\
\hline
\end{tabular}

Note. ${ }^{*} p<.05$

\section{MANOVA}

Using the factor scores from both factor analyses, a Multiple Analysis of Variance (MANOVA) was performed to see if there was any significant effect for the independent variable of school year. The dependent variables in the statistical procedure were the three factors for the FLRAS and the two factors for the FLCAS. A significant effect for the independent variable of year was found $(p<.008 ; d f=10,488)$ and the Wilks' Lamda was 908 . Univariate analysis indicated that the significant factor in this analysis was FLRA1 (Familiarity with English Vocabulary and Grammar), as shown in Table 7.

Table 6: MANOVA Results

\begin{tabular}{lccccc}
\hline Source & $S S$ & $d f$ & MS & $F$ & $P$ \\
\hline FLRA1 & 3.9133 & 2 & 0.9824 & 3.9832 & .0198 \\
FLRA2 & 1.6522 & 2 & 1.0008 & 1.6508 & .1940 \\
FLRA3 & 2.8026 & 2 & 0.9935 & 2.8209 & .0615 \\
FLCA1 & 2.5408 & 2 & 0.9916 & 2.5623 & .0792 \\
FLCA2 & 0.4959 & 2 & 1.0081 & 0.4919 & .6121 \\
\hline
\end{tabular}


Table 7: MANOVA Univariate Analysis Results

\begin{tabular}{lccccc}
\hline Effect & Wilks' Lambda & Rao's R & df & df 2 & $p$ \\
\hline 1 & 0.908 & 2.415 & 10 & 488 & 0.008
\end{tabular}

\section{Discussion}

Unlike Saito et al. (1999), who found a significant relationship between the overall FLCAS and FLRAS, we found almost no statistically significant correlation between the two scales. While Saito et al. claim that students with high general FL anxiety tend to have high FL reading anxiety, our findings indicate that FL reading anxiety is very specific and independent of more general types of FL anxiety. Items from both measures loaded on different components except for "low self-confidence," which was found to be a significant component of both anxiety scales. We found two subcomponents in the FLCAS that we labeled General Classroom Performance Anxiety (FLCA1) and Low Self-Confidence in Speaking English (FLCA2) and three subcomponents in the FLRAS that we labeled Familiarity with English Vocabulary and Grammar (FLRA1), Reading Confidence/Enjoyment (FLRA2), and Language Distance (FLRA3). When the items in the two measures were examined further based on the factors above, however, there were significant relationships between the FLCA1 and FLRA3, the FLCA2 and the FLRA2, and the FLCA2 and the FLRA3. Although the FLCAS and the FLRAS are independent of each other, they share some latent anxiety elements.

Previous research supports the idea that anxiety in foreign language learning is a multi-faceted construct. Those constructs seem to vary depending on target language and different learning settings. Aida (1994) administered the FLCAS to a class of students of Japanese and obtained four factors (Speech Anxiety and Fear of Negative Evaluation, Fear of Failing the Class, Comfortableness in Speaking with Native Speakers of Japanese, and Negative Attitude toward Japanese Class), none of which was similar to any of the factors we found in the FLCAS. On the other hand, Cheng et al. (1999) examined the FLCAS and the SLWAT and found low self-confidence as a significant component in both measures. Moreover, their two subcomponents of the FLCAS were similar to the subcomponents we obtained in the FLCAS, although Cheng et al. found the low confidence dimension as the primary component. 
As for the FLRAS, we cannot compare our findings to other studies because, thus far, only a few researchers have recognized the possible existence of FL reading anxiety. After administering the FLRAS, Saito et al. (1999) also claimed that FL reading is an anxiety-provoking activity. Their study, however, was conducted in French, Russian, and Japanese language classrooms. Anticipating that two aspects, a) unfamiliar scripts and writing systems and b) unfamiliar cultural material, would have an impact on learners' anxiety, they simply compared means of the data from each language group. Their participants, however, were in first-semester university classes, that is, relatively new learners of a foreign language. When dealing with English majors in Japan, aspect a) above may not be applicable. Most students have studied English since junior high school and are familiar with the English alphabet and symbols. Therefore, some items in the FLRAS may not have been suitable. For example, "funny letters and symbols" in item 10 and "new symbols" in item 11 may not have been understood precisely.

As our data analysis suggested, the first subcomponent of FLRAS (FLRA1, Familiarity with English Vocabulary and Grammar) was the most significant factor in marking difference by school year. It seems that first-year students tend to be more concerned about unfamiliar topics, unknown sounds, words, and grammar (displayed in items 5 , 6,7 , and 8). They are likely to focus on details rather than the big picture of the reading. As Saito et al. (1999) found, "the fact that students feel they should understand everything and experience anxiety whenever they encounter unfamiliar words and grammar" (p. 214) was most prevalent in the first-year students.

We should, however, point out the limitations of this study. The major limitation of this study is the low reliability of both questionnaires, and it is this low reliability that may have had an effect on the findings of the principal component analysis. There are a number of possibilities why the reliability for these two scales was low. Possible sources of variance include variance due to questionnaire administration, variance attributable to the participants, and variance attributable to the questionnaire items.

The results need to be interpreted with caution because although students were told to answer about English classes in general, they may have responded based on the specific class they were attending at that time. In addition, whether the administrator was Japanese or nonJapanese may have influenced subject responses to certain items. It must also be noted that responses might have been different had the questionnaires been administered at the beginning or end of the semester, or together (as was done with Saito et al., 1999). 
Variance attributable to the participants and different curricula could have somehow affected their anxiety reactions as well. Third-year students do not actually have conversation class, but may be required to speak in a more challenging situation in reading/writing classes. Firstyear students learn to read in an integrated "four-skills" course, so they were not really exposed to extensive reading yet. We also did not take students' individual experiences or proficiency into consideration.

Another source of variance to consider is the sensitivity of responses to item wording. Although the two scales contain sets of items that are intended to measure the same type of anxiety, our participants responded differently to the items such as FLCAS item 3 ("I tremble when I know that I'm going to be called on in English class" $)(M=2.72, S D=$ 1.10) and item 20 ( ${ }^{4} \mathrm{I}$ can feel my heart pounding when I am going to be called on in my English class") $(M=3.10, S D=1.10)$. Item 4 ("It frightens me when I don't understand what the teacher is saying in English") $(M=3.06, S D=1.21)$ was also marked differently from its counterpart, item 29 ("I get nervous when I don't understand every word the English teacher says" $)(M=3.32, S D=1.04)$. We observed a more noticeable difference in the FLRAS, displayed in item 1 ("I get upset when I'm not sure whether I understand what I'm reading in English" $(M=2.25 S D=0.95)$ and item 7 ("When reading English, I get nervous and confused when I don't understand every word" $)(M=3.18$, $S D=1.10$ ). Thus, one plausible explanation for our low reliability is a lack of exact agreement among the intended items.

With respect to the two scales used, the FLRAS is not as thoroughly tried and tested as the FLCAS. The especially low reliability displayed by the FLRAS in our study raises the question of the applicability of this scale, in its present form, to English majors in Japan. Also, the wording in the Japanese translation, although carefully constructed, may have somehow affected the reliability.

\section{Conclusion}

Although reading is considered a private task and thought to be unsusceptible to anxiety (Macintyre et al., 1997), our findings show the existence of apprehension towards FL reading, which is distinguishable from general FL anxiety. When the items were examined further by factor analysis, our five-factor solution indicated a complex feature of FL anxiety. We found some relationships between the subcomponents of the two scales; however, the FLCAS and the FLRAS, being far from identical, can be seen as measuring different constructs. The three components we found in the FLRAS are related to anxiety specific to 
FL reading, and they describe important types of anxiety that may arise in FL reading classrooms.

Regarding our second research question, our data provide tentative support for the view that reading anxiety due to limited familiarity with English grammar and vocabulary is greater among first-year students than second- or third-year students. One possible explanation for this may be the attention paid to grammar and vocabulary when preparing for entrance exams. It could be that this attention to grammar and vocabulary lessens as students progress through their four years of study. If this is the case, then teachers may wish to specifically address this reading anxiety in the first year, possibly by focusing more on fluency activities than on accuracy activities, for example.

Whether or not our interpretation of our findings is correct, we hope that our study has shown the importance of establishing the validity and reliability of a questionnaire for each new population and translation. Based on our results it is clear that the surveys and the items therein should be redesigned. In addition, more qualitative research, such as interviews and classroom observation, would help to shed some light on the validity of the models created by this study. By using multiple methods of data collection and data analysis, it may be possible to come to a clearer understanding of FL reading anxiety and its relationship to general FL anxiety.

\section{Acknowledgements}

We would like to express our sincere gratitude to our colleagues and their students who devoted their time to our research project. We would also like to thank the editor and the two anonymous reviewers of JALT Journal for their insightful comments on the earlier draft of this paper.

Sae Matsuda teaches English and Japanese at Kyoto Sangyo University. Her research interests include affective variables in L.2 (English and Japanese), action research, and CALL.

Peter Gobel is an Associate Professor at Kyoto Sangyo University. His research interests include communication strategy training and use and narrative discourse structure. Questions and comments can be sent to <pgobel@cc.kyoto-su.ac.jp>. 


\section{Note}

Although values close to zero are desired for both kurtosis and skewness, the standard error of measurement for kurtosis in this study was .154 , and the standard error of measurement for skewness was .308 . Based on these values, the obtained skewness values were compared with zero using a $z$ distribution (see Tabachnick \& Fidell, 1996, p. 72). No significant kurtosis or skewness was found at $\mathrm{a}=.01$.

\section{References}

Aida, Y. (1994). Examination of Horwitz, Horwitz, and Cope's construct of foreign language anxiety: The case of students of Japanese. Modern Language Journal, 78, 155-168.

Alpert, R., \& Haber, R. N. (1960). Anxiety in academic achievement situations. Journal of Abnormal and Social Psychology, 61, 207-215.

Bailey, K. M. (1983). Competitiveness and anxiety in adult second language learning: Looking at and through the diary studies. In H. W. Seliger \& M. H. Long (Eds), Classroom Oriented Research in Second Language Acquisition (pp. 67-102). Rowley, MA: Newbury House.

Chapelle, C., \& Roberts, C. (1986). Ambiguity tolerance and field independence as predictors of proficiency in English as a second language, Language Learning, 36, 27-45.

Chastain, K. (1975). Affective and ability factors in second-language acquisition. Language Learning, 25, 153-161.

Cheng, Y., Horwitz, E. K., \& Schallert, D. L. (1999). Language anxiety: Differentiating writing and speaking components. Language Learning, 49, 417-446.

Daly, J. A. \& Miller, M.D (1975a). The empirical development of an instrument of writing apprehension. Research in the Teaching of English, 9, 242-249.

Daly, J. A., \& Miller, M.D. (1975b). Further studies in writing apprehension: SAT scores, success expectations, willingness to take advanced courses, and sex differences. Research in the Teaching of English, 9, 250-256.

Desrochers, A. M., \& Gardner, R. C. (1981). Second language acquisition: An investigation of a bicultural excursion experience. In R. Schwarzer (Ed.), Self-related cognition in anxiety and motivation (pp. 35-54). Hillsdale, NJ: Erlbaum.

Ely, C. M. (1986). An analysis of discomfort, risk-taking, sociability, and motivation in the L2 classroom. Language Learning 36, 1-25.

Eysenck, M. W. (1979). Anxiety, learning, and memory: A reconceptualization. Journal of Research in Personality, 13, 363-385. 
Gardner, R. C., \& MacIntyre, P. D. (1992). A student's contributions to second language learning. Part I: Cognitive variables. Language Teaching, 25, 211 220.

Gardner, R. C., Smythe, P. C., \& Brunet, G. R. (1977). Intensive second language study: Effects on attitudes, motivation, and French achievement Language Learning, 27, 243-261.

Gardner, R.C., Smythe, P. C., \& Clement, R. (1979). Intensive second language study in a bicultural milieu: An investigation of attitudes, motivation, and language proficiency. Language Learning, 29, 305-320.

Gardner, R. C., Smythe, P. C., Clement, R., \& Gliksman, L. (1976). Second language acquisition: A social psychological perspective. Canadian Modern Language Review, 32, 198-213.

Horwitz, E. K. (1988). The beliefs about language learning of beginning university foreign language students. Modern Language Journal, 72, 283-294.

Horwitz, E. K., Horwitz, M.B., \& Cope, J. A. (1986). Foreign language classroom anxiety. Modern Language Journal, 70, 125-132.

Kline, P. (1994). An easy guide to factor analysis. London: Routledge.

MacIntyre, P. D., \& Gardner, R. C. (1989). Anxiety and second language leaning: Toward a theoretical clarification. Language Learning, 39, 251-275.

MacIntyre, P. D., \& Gardner, R. C. (1991a). Language anxiety: Its relation to other anxieties and to processing in native and second languages. Language Learning, 41, 513-534.

MacIntyre, P. D., \& Gardner, R. C. (1991b). Methods and results in the study of anxiety in language learning: A review of the literature. Language Learning, 41, 85-117.

MacIntyre, P. D., \& Gardner, R. C. (1994a). The effects of induced anxiety on three stages of cognitive processing in computerized vocabulary learning. Studies in Second Language Acquisition, 16, 1-17.

MacIntyre, P. D., \& Gardner, R. C., (1994b). The subtle effects of language anxiety on cognitive processing in the second language. Language Learning, 44, 283-305.

MacIntyre, P. D., Noels, K. A., \& Clement, R. (1997). Biases in self-ratings of second language proficiency: The role of language anxiety. Language Learning, 47, 265-287.

Mejias, H., Applebaum, R. L., Applebaum, S. J., \& Trotter, R. T. (1991). Oral communication apprehension and Hispanics: An exploration of oral communication apprehension among Mexican American students in Texas. In E. K. Horwitz \& D. J. Young (Eds.), Language anxiety: From theory and research to classroom implications (pp, 87-97), Englewood Cliffs, NJ: Prentice-Hall.

Phillips, E. (1992). The effects of language anxiety on students' oral test performance and attitudes. Modern Language Journal, 76, 14-26. 
Price, M. L. (1991). The subjective experience of foreign language anxiety: Interviews with highly anxious students. In E. K. Horwitz \& D. J. Young (Eds.), Language anxiety: From theory and research to classroom implications (pp. 101-108). Englewood Cliffs, NJ: Prentice-Hall.

Saito, Y., Garza, T., \& Horwitz, E. (1999). Foreign language reading anxiety. Modern Language Journal, 83, 202-218.

Saito, Y., \& Samimy, K. (1996). Foreign language anxiety and language performance: A study of learner anxiety in beginning, intermediate, and advanced-level college students of Japanese. Foreign Language Annals, 29, 239-251.

Samimy, K. K., \& Tabuse, M. (1992). Affective variables and a less commonly taught language: A study in beginning Japanese classes. Language Learning, 42, 377-398.

Spielberger, C. D. (1983). Manual for the State-Trait Anxiety Inventory (Form Y). Palo Alto, CA: Consulting Psychologists Press.

STATISTICA for the Macintosh, (1994). Volume II. Tulsa, OK: StatSoft, Inc..

Steinberg, F. S., \& Horwitz E. K. (1986). The effects of induced anxiety on the denotative and interpretive content of second language speech. TESOL Quarterly, 20, 131-136

Tabachnick, G., \& Fidell, S. (1996). Using multivariate statistics. Third edition. New York: Harper Collins.

Tobias, S. (1986). Anxiety and cognitive processing of instruction. In R. Schuwarzer (Ed.), Self-related cognition in anxiety and motivation (pp. 35 54). Hillsdale, NJ: Erlbaum.

Young, D. J. (1991). Creating a low-anxiety classroom environment: What does language anxiety research suggest? Modern Language Journal, 75, 426-439.

(Received February 14, 2001; revised June 6, 2001) 